\title{
«Zero Suicide» - A model for reducing suicide in United States behavioral healthcare
}

\author{
By Christa D. Labouliere, Prabu Vasan, Anni Kramer, \\ Gregory Brown, Kelly Green, Mahfuza Rahman, \\ Iamie Kammer, Molly Finnerty, \& Barbara Stanley
}

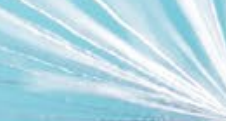

\section{ABSTRACT}

Suicide is a serious public health concern in the US, especially for those served in outpatient behavioral health. Over the past decade, there has been a dramatic increase in US suicide rates, and a significant proportion of those dying by or attempting suicide were treated in outpatient behavioral healthcare within the prior year. In response, the US Action Alliance released the National Strategy for Suicide Prevention in 2012, a key tenet of which is the «Zero Suicide» (ZS) model. ZS provides resources for administrators and providers to create a systematic approach to quality improvement for suicide prevention in healthcare systems via seven essential elements (Lead, Train, Identify, Engage, Treat, Transition, Improve). In this paper, we describe the ZS model, as well as our operationalization of the model in an NIMH-funded study in $\sim 170$ free-standing New York State outpatient behavioral health clinics, serving $>80000$ patients. This study is the largest implementation and evaluation of the ZS approach ever conducted in outpatient behavioral health. Evaluation of ZS implementation in «real-world» clinical settings will provide crucial insight regarding broader dissemination and inform how to best adopt empirically-supported care for suicidal patients in outpatient behavioral health, thereby reducing tragic and preventable loss of life.
Selvmord er et alvorlig folkehelseproblem i USA, spesielt for de som mottar poliklinisk behandling i psykisk helsevern. Det har vært en dramatisk økning i amerikanske selvmordsrater det siste tiåret, og en signifikant andel av de som forsøker å ta eller tar sitt eget liv mottok poliklinisk behandling i psykisk helsevern innenfor det samme året. Som mottiltak publiserte The US Action Alliance en nasjonal strategi for selvmordsforebygging i 2012 med et grunnprinsipp om nullvisjon, eller Zero Suicide på engelsk (ZS). Nullvisjonsmodellen tilbyr hjelpemidler for helsearbeidere for å skape en systematisk tilnærming til kvalitetsforbedring i selvmordsforebygging i helsevesenets systemer gjennom syv essensielle elementer (lede, lære opp, identifisere, engasjere, behandle, følge opp, forbedre). I denne artikkelen vil vi beskrive nullvisjonsmodellen, samt vår implementering av modellen i en studie finansiert av NIMH (Nasjonalt institutt for psykisk helse i USA) i omtrent 170 frittstående institusjoner for psykisk helsevern i delstaten New York, som til sammen omfattet over 80000 pasienter. Denne studien er den største implementeringen og evalueringen av nullvisjonstilnærmingen som noensinne er blitt gjennomført i psykiatriske poliklinikker. Å evaluere en slik nullvisjonsstrategi i kliniske settinger kan gi viktig kunnskap til bruk i bredere implementering og gi mer kunnskap om hvordan innføre kunnskapsbasert poliklinisk behandling for suicidale pasienter i psykisk helsevern, og slik redusere forekomsten av tragiske dødsfall. 
WORLDWIDE, someone dies by suicide every 40 seconds. More than 800 ooo people die by suicide annually, and for every death there are an additional 10-25 attempts (World Health Organization [WHO], 2017). In the United States, suicide is the 1oth leading cause of death, and suicide rates are $22 \%$ higher than global averages (Center for Disease Control and Prevention [CDCP], 2017). U.S. suicide rates increased a staggering $25 \%$ over the past decade while other leading causes of death declined (CDCP, 2016). In 2016 alone, nearly 45000 Americans died by suicide and one million made attempts (CDCP, 2017). Given the scope of this public health issue, the need for prevention has been repeatedly affirmed (U.S. Department of Health \& Human Services [U.S. DHHS], 2011; 2012).

In response to this enormous public health issue, the National Action Alliance for Suicide Prevention (NAASP) was established in 2010. The National Action Alliance is a public-private partnership advancing the National Strategy for Suicide Prevention, a report published in 2012 by the U.S. Surgeon General in partnership with the United States Department of Health and Human Services, Substance Abuse and Mental Health Services Administration, the Suicide Prevention Resource Center, and a task force consisting of national and international suicidology experts (U.S. DHHS, 2012). While the National Strategy for Suicide Prevention advocates a comprehensive approach to suicide prevention involving community, school, primary care, emergency departments, inpatient units, and outpatient behavioral health settings, the National Action Alliance has identified healthcare systems as particularly critical venues for suicide prevention because suicidal patients often receive services in the period leading up to their attempt or death, providing an opportunity for identification and connection to treatment (U.S. HHS, 2012).
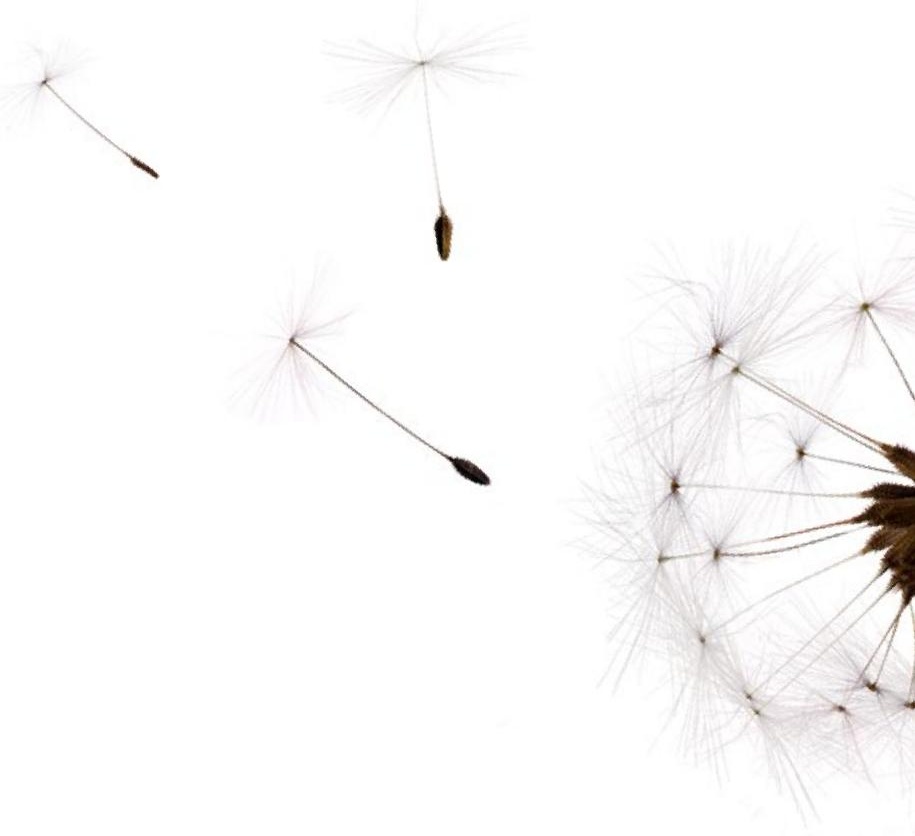

Unfortunately, suicidal patients often «fall through the cracks», due in part to a fragmented American healthcare system (SPRC, 2017). Unlike in Norway, healthcare is not typically provided or overseen by the government in the United States (except for persons with significant disabilities or those living in poverty and requiring government assistance), and the majority of healthcare facilities are independent and privately-run. The majority of individuals pay for their health insurance premiums out-of-pocket, either through state-specific or federal insurance marketplaces or through group plans administered by private insurance companies that are offered and subsidized by their employers. While the Affordable Care Act of 2010 mandated that all Americans must carry health insurance, millions of individuals still struggle to access adequate, affordable healthcare (American College of Emergency Physicians, 2017). Further, idiosyncratic variations exist in insurance coverage, and different often-unaffiliated facilities are responsible for the care of physical, behavioral, and substance-related concerns; as a result, poor continuity of care and communication among providers is common (U.S. DHHS, 2011).

Even those receiving care often do not receive what is required to prevent or resolve suicidal crises. Between $20-80 \%$ of all persons dying by suicide in the U.S. accessed care in the year prior to their death (Ahmedani et al., 2014; Luoma, Martin, \& Pearson, 2002), and nearly half within 30 days (Ilgen et al., 2012; a finding that has been replicated in other nations; Isometsa et al., 1995). While many reasons exist why people receiving services still die by suicide, three potential causes were identified by the National Strategy for Suicide Prevention: 1) detection of suicide risk is inadequate; 2) evidence-based, suicide-specific interventions are not deployed; and 3 ) intensity of care is not increased 
during high risk periods (U.S. DHHS, 2012). While great strides have been made in the past ten years in identifying «best practices» for suicide prevention (Brown et al., 2005; Fowler et al., 2012; Jobes et al., 2005; Michel et al., 2017; Michel \& Gysin-Maillart, 2015; Linehan et al., 2006; Luxton et al., 2013; Pisani et al., 2016; Posner et al., 2011), a striking gap remains between the development of these innovations and what services the majority of suicidal individuals in the U.S. actually receive. Experts in suicide prevention have long recommended universal screening with validated measures at regular intervals across varied settings to better identify those who may be at-risk for suicide, but the majority of individuals seen in healthcare settings do not receive any screening, let alone frequent screenings using standardized metrics (Posner et al., 2011). The field has also moved away from prediction of who will engage in suicidal behaviors, and shifted to a prevention-oriented approach in which those who are identified as being at elevated risk receive comprehensive suicide risk assessments that weigh distal and proximal risk and protective factors to identify potential fluctuations in suicide risk over time and inform subsequent treatment planning and interventions (Jobes et al., 2005; Pisani et al., 2016). However, the majority of clinicians are not trained in this orientation, many systems rely on risk status for triage, and even those patients who are effectively identified as being at high risk often do not receive specialty or more intensive mental health care.

Beyond best practices in assessment, research has also shown that a better understanding of the suicidal state and suicide-specific interventions shows significant promise in resolving suicidal urges, whereas treating underlying diagnoses alone does not typically resolve suicidal ideation and behaviors (Brown et al., 2005, Linehan et al., 2006; Michel \& Gysin-Maillart, 2015). Unfortunately, despite the development of evidence-based, suicide-specific treatments and clinician guidelines (AESHI Working Group, 2018), the majority of clinicians working with suicidal individuals do not have sufficient training in how to provide these interventions or build strong, collaborative relationships with suicidal patients (Brown et al., 2005, Linehan et al., 2006; Michel \& Gysin-Maillart, 2015; Michel \& Jobes, 2010). In response to these gaps between science and practice, the National Action Alliance sought to provide recommendations for improving suicide care in healthcare systems, especially in regard to adequate procedures for detection of suicide risk, use of evidence-based, suicide-specific interventions, and greater intensity of care, monitoring, and patient engagement during their highest risk periods (U.S. DHHS, 2012). A key method of disseminating best practices in suicide care was the «Zero Suicide» Initiative (ZS; Suicide Prevention Resource Center, 2017; zerosuicide.sprc.org).

\section{The «Zero Suicide» Initiative}

ZS is a key component of the National Strategy for Suicide Prevention and priority of the National Action Alliance that aims to bridge gaps in practice. ZS is a strategic framework for creating a systematic approach to suicide prevention and quality improvement in the healthcare system with the aspirational goal of «zero suicides.» The foundational belief of ZS is that suicide deaths for individuals receiving care within health and behavioral health systems are preventable. The few healthcare systems that have implemented and evaluated ZS-like approaches demonstrated notable reductions in suicide deaths (Centerstone, 2016; Hampton, 2010). It must be noted that these studies were correlational and preliminary; it is extremely challenging to prove that a reduction of suicides is causally related to a specific suicide prevention effort, and only large-scale, controlled evaluations of ZS procedures will establish their effectiveness. However, reductions of greater than $70 \%$ in the year after unveiling ZS interventions are certainly promising. The ZS model provides guidance on how to best implement «best practices» in «real-world» settings. ZS is comprised of seven essential elements for an effective, coordinated system for suicide care; four of these elements focus on how the patient should be treated and the remaining three relate to implementation factors (see Table 1).

The first implementation element, Lead, emphasizes the need to engage leadership and administration to create a culture change about suicide prevention. The onus is placed on leadership to put policies in place that foster a transparent, blame-free environment

\section{TABLE 1. ZS Elements and their descriptions}

\begin{tabular}{|l|l|}
\hline Element & Description \\
\hline Implementation Elements & $\begin{array}{l}\text { Create organizational culture } \\
\text { change about suicide prevention } \\
\text { Develop a suicide prevention } \\
\text { competent workforce }\end{array}$ \\
\hline TRAIN & \begin{tabular}{l} 
Data-driven quality improvement \\
\hline IMPROVE
\end{tabular} \\
\hline Clinical Elements & $\begin{array}{l}\text { Screening and assessment } \\
\text { of suicide risk } \\
\text { Ensuring pathways to care }\end{array}$ \\
\hline IDENTIFY & $\begin{array}{l}\text { Using effective evidence-based } \\
\text { best practices }\end{array}$ \\
\hline ENGAGE & \begin{tabular}{l} 
Continuing contact and follow-up \\
\hline TREAT
\end{tabular} \\
\hline TRANSITION
\end{tabular}


where suicide prevention is a systems issue and not the personal responsibility of individual staff members. This shifts emphasis away from liability or fear toward a safety-focused team approach, wherein identification and improvement of barriers to optimal care are everyone's responsibility. The second implementation element, Train, highlights the importance of developing a competent suicide prevention workforce. The ZS model stresses that every member of the workforce (not only mental health professionals) should receive training on the signs of suicide risk and how to interact with suicidal individuals effectively, with different staff roles requiring different competencies. Lastly, the final implementation element, Improve, emphasizes the need for data-driven quality improvement. Before implementing new procedures, organizations assess their current clinical practices, attitudes, and training to determine needs and knowledge/practice gaps. Leadership then develops an implementation plan based on identified needs, and employs systematic data collection to evaluate efforts, continually assess progress and model fidelity, encourage accountability, and inform revisions.

In addition to implementation elements, the ZS model also recommends four clinical elements. The Identify element provides guidelines for evidence-based screening and assessment of suicide risk for all patients at intake and regular intervals. The Engage element ensures pathways to care for patients at elevated risk, and recommends the creation of a personalized Suicide Care Management Plan that includes frequent reassessment, specialized treatment, and greater intensity of clinical contact. The Treat element stresses the importance of using evidence-based, suicide-specific interventions, including brief interventions to maintain immediate safety (such as safety planning and means reduction counseling), and longer-term interventions to directly target suicidal thoughts and behaviors. Lastly, the Transition element highlights continuity of care and close monitoring of suicidal individuals, both between clinical contacts and during care transitions (e.g., hospital or ED discharge, etc.). For more detail, see: http:// zerosuicide.sprc.org/toolkit.

\section{A Large-Scale Implementation of Zero Suicide in Outpatient Behavioral Health}

While emergency departments (ED) and inpatient units have historically been settings associated with crisis care, outpatient behavioral health is increasingly recognized as a critical venue for improved suicide care. In the United States, outpatient behavioral health clinics are typically freestanding entities that focus on mental health or substance abuse treatment. While these clinics may be in the same healthcare system as primary care or hospital providers, many are independent public or private organizations. While individuals may receive inpatient or residential treatment for particularly severe presentations or in times of acute crisis, the majority

of care for mental disorders is provided in outpatient behavioral health settings. Suicide rates in these settings are 100 times higher than those of the general population (Brown et al., 2000). At any time, $\approx 15 \%$ of outpatient behavioral health patients endorsed suicidal ideation in the past week (Trivedi et al.,

\section{While individuals} may receive inpatient or residential treatment for particularly severe presentations or in times of acute crisis, the majority of care for mental disorders is provided in outpatient behavioral health settings 2013), 55 \% report lifetime suicidal ideation, and more than $25 \%$ made a suicide attempt (Harkavy-Friedman, 1993). These high rates are particularly alarming since outpatients experiencing suicidal ideation or a suicide attempt are more likely to eventually die by suicide (Wenzel et al., 2011). Given that behavioral health patients are seen over a longer period of

time than inpatient or ED patients, the opportunities to intervene are greater; thus, improving prevention practices in outpatient behavioral health holds promise for reducing suicide.

As the ZS model is being promoted nationally, the National Institute of Mental Health (NIMH) funded grants evaluating the effectiveness of ZS interventions. Herein, we describe our implementation of the ZS model in New York State (NYS) behavioral healthcare clinics, the largest implementation and evaluation of the ZS model ever conducted. This implementation is a continuous quality improvement project undertaken by the NYS Office of Mental Health Bureau of Evidence Based Services and Implementation Science, with funding from the NIMH to test and evaluate implementation strategies (NIMH grant \#: Ro1-MH112139; PI: Stanley).

\section{NYS as a test system for outpatient ZS implementation} NYS is a strong location for testing implementation efforts, because the state's size, regional and population diversity, and established administrative databases allow for a large-scale, generalizable evaluation of ZS. While the suicide rate is relatively low, NYS ranks 5 th in the nation for number of deaths (CDCP, 2017) given the population density. The suicide rate is also markedly variable across the state - while rates of suicide death are lower than the national average in the populous New York City metropolitan region, almost $50 \%$ of counties in NYS have suicide rates higher than the national average, especially in rural northern and western upstate regions. Rates among outpatient behavioral health patients climb even higher (58/100 oo० in some counties; NYS Office of Mental Health, 2015). 
TABLE 2. Characteristics of Medicaid enrolled patients served in New York State participating clinics

\begin{tabular}{|c|c|}
\hline Characteristics & $\begin{array}{l}\text { Percentage } \\
N=73732\end{array}$ \\
\hline \multicolumn{2}{|l|}{ Age } \\
\hline Youth $(<18)$ & $29,6 \%$ \\
\hline Adults $(18+)$ & $70,4 \%$ \\
\hline \multicolumn{2}{|l|}{ Gender $^{1}$} \\
\hline Male & $46,2 \%$ \\
\hline Female & $53,8 \%$ \\
\hline \multicolumn{2}{|l|}{ Race and Ethnicity ${ }^{2}$} \\
\hline Caucasian or White & $51,0 \%$ \\
\hline African-American or Black & $23,3 \%$ \\
\hline Hispanic or Latinx & $10,5 \%$ \\
\hline Asian or Asian-American & $2,1 \%$ \\
\hline Other/Unknown & $13,1 \%$ \\
\hline \multicolumn{2}{|l|}{ Region $^{3}$} \\
\hline Rural & $44,0 \%$ \\
\hline Urban & $56,0 \%$ \\
\hline \multicolumn{2}{|l|}{ Primary Diagnoses $^{4}$} \\
\hline Depressive disorder & $25,4 \%$ \\
\hline Schizophrenia-spectrum disorder & $16,0 \%$ \\
\hline Externalizing disorder (ADHD or Conduct) & $13,2 \%$ \\
\hline Anxiety disorder & $9,9 \%$ \\
\hline Bipolar disorder & $9,5 \%$ \\
\hline Personality disorder & $0,5 \%$ \\
\hline Other ${ }^{5}$ & $25,5 \%$ \\
\hline Comorbid substance treatment ${ }^{5}$ & $10,5 \%$ \\
\hline
\end{tabular}

Note: This analysis includes Medicaid enrolled individuals, with one or more service at a participating mental health clinic (177 clinics, 90 provider agencies participating as of April 1, 2017) between November 1st, 2015 and November 1st, $2016(N=86080)$, excluding individuals over 64 years or without continuous Medicaid eligibility during the year of observation $(n=73732)$. All data is derived from Medicaid claims and encounters.

1 Information on transgender and non-binary gender-identified individuals was not available from Medicaid databases.

2 Information on race and ethnicity (i.e., White vs. Black Hispanic) was not available separately from Medicaid databases.

${ }^{3}$ A county was defined as urban if its population density was greater than 1000 people per square mile according to the 2010 Census.

${ }^{4}$ Determined using the most prevalent diagnosis assigned to the individual in Medicaid claims during the year of observation.

5 Includes all diagnoses with $<0,5 \%$.

${ }^{6}$ Includes those with any substance use service during the year.
Nearly $45 \%$ of those dying by suicide in NYS were seen within a month of their death in an outpatient behavioral health clinic (NYS Office of Mental Health, 2016). The quality of care in New York is also representative of outpatient care across the United States, in that most clinicians have little or no specialized training in suicide-specific interventions, few clinics have established systematic protocols for identifying, treating, and monitoring patients at elevated suicide risk, and no universal system for documenting and sharing information is in place across treatment settings (NYS Office of Suicide Prevention, 2016). Thus, we have aimed to address all of these deficits through our implementation of the ZS model.

\section{Participating clinics}

As of April 1, 2017, 177 licensed freestanding or stateoperated mental health clinics were participating in this project. Clinics represent 90 provider agencies, over 3500 clinicians, and serve approximately 86 ooo Medicaid-enrolled patients each year (see Table 2 for patient characteristics). Clinics elected to participate through a statewide continuous quality improvement project led by the NYS Office of Mental Health Bureau of Evidence Based Services and Implementation Science program and receive a small Medicaid claims-rate incentive $(\sim 4 \%)$.

\section{AIM-SP clinical procedures}

All participating clinics agreed to implement our operationalization of the ZS clinical procedures, called the Assess, Intervene, and Monitor for Suicide Prevention (AIM-SP; Stanley, 2017) program of suicide-safer care (see Figure 1). AIM-SP strives to provide a basic level of care for all patients, including universal screening and comprehensive risk assessment on a regular basis for all patients, and engagement of high-risk patients on a Suicide-Safer Care Pathway (SSCP) with specialized care and increased contact.

\section{Assessment for all patients}

All patients are screened for suicide risk at intake, quarterly treatment plan review, and as clinically-indicated (i.e., whenever there is an abrupt change in clinical status or if the clinician is concerned) using the highly-validated Columbia Suicide Severity Rating Scale (C-SSRS; Posner et al., 2011). At intake, the C-SSRS asks about both lifetime and recent suicidal thoughts and behaviors; subsequent timeframes are since the last administration. Patients also receive a comprehensive suicide risk assessment at intake, after positive screens, or as clinically-indicated, providing broader case conceptualization and creating an individualized profile of chronic/ distal and acute/proximal risk and protective factors. Risk assessment is completed in the same session as a positive screen or shortly thereafter.

Intervention and monitoring for patients on the 
SSCP. If a patient is deemed to be high-risk during assessment, they are placed on the SSCP, a package of enhanced outpatient care that involves frequent reassessment and monitoring, greater intensity of clinical contact, and specialized interventions. Patients are placed on the SSCP if they endorse suicidal intent, plan, or behavior within the past 90 days (i.e., a «Yes» response to any of questions 4-6 on the C-SSRS screener); patients may also be placed on or removed from the SSCP based on clinical judgment. SSCP designation is clearly denoted in the medical record.

Before the patient leaves the initial clinical interaction, clinicians must determine which actions must be taken immediately to keep the patient safe until the next session. This includes administering the 6-step Stanley-Brown Safety Planning Intervention (which includes provision of crisis information and means reduction counseling), and may involve including friends or family, if appropriate. Clinicians also provide psychoeducation about the nature of suicide risk, and brief the patient regarding the requirements of treatment on the SSCP and the rationale for these interven- tions. In subsequent sessions, clinicians construct a treatment plan that directly addresses suicidal thoughts and behavior. If clinicians are trained in suicide-specific interventions, these approaches are recommended; alternatively, clinicians can utilize their existing orientation and skillset to directly target modifiable risk factors and enhance protective factors, as informed by comprehensive suicide risk assessment. Clinicians maintain at least weekly sessions with all patients on the SSCP, re-screen patients at each session, and revise the safety plan as needed.

If patients miss scheduled appointments, clinicians make outreach contact to ensure safety and maintain continuity of care. This contact likely consists of a phone call, but could take the form of text messaging, emails, or home visits based on clinic policy. When making outreach contact, the purpose is to show concern over the patient's absence, assess mood state and current suicide risk, review the safety plan and crisis resources, problem-solve barriers to using the safety plan and attending treatment, and re-engage by scheduling an appointment as soon as possible. When

FIGURE 1. Clinical procedures of the Assess, Intervene, and Monitor for Suicide Prevention (AIM-SP) program of suicide-safer care, an operationalization of the Zero Suicide model for outpatient behavioral health clinics

\section{$\underline{A}$ SSESS}



\section{INTERVENE \& MONITOR}

\section{SUICIDE-SAFER CARE PATHWAY}

Entry: Suicidal ideation with intent or plan or suicidal behavior in the past 90 days -OR-Clinical judgment Exit: No ideation with intent or plan and no suicidal behavior for 90 days -OR- clinical judgment

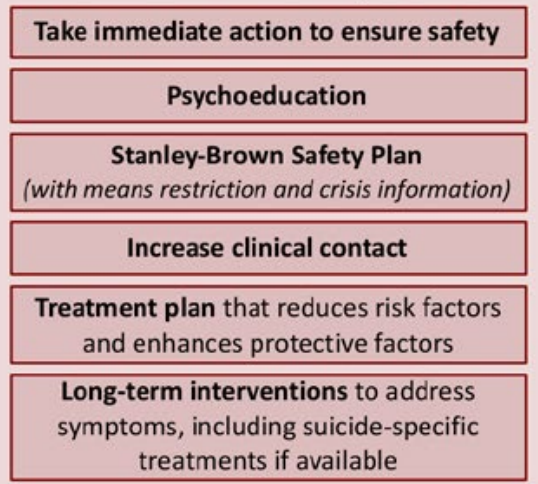

Provide crisis information, including after hours numbers, LIFELINE, \& local ED/CPEP

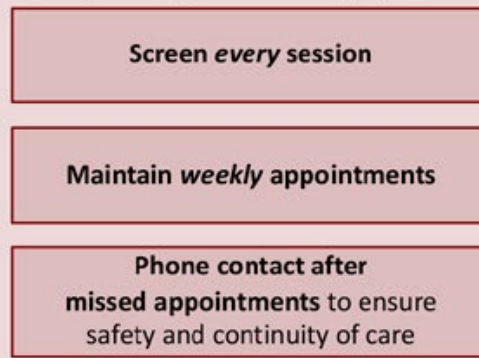

Session within $\mathbf{7 2}$ hours of discharge from the ED or inpatient unit

Re-screen quarterly at treatment plan review or as clinically indicated
High Risk: SSCP procedures are required

Moderate Risk: SSCP procedures are strongly recommended

Low Risk: Treatment as usual, with SSCP procedures as clinically indicated 
patients on the SSCP have an ED visit or hospitalization, they are prioritized to receive an appointment within 72 hours of discharge (a particularly high-risk period for suicide). Clinicians strive for contact with other treatment providers to ensure «warm handoffs» and continuity of care during care transitions. Patients are eligible to exit the SSCP after 90 days free from suicidal intent, plan, behavior, ED visits, or inpatient hospitalizations or should the clinician determine that the level of care is no longer indicated.

\section{Intervention and monitoring for patients not on the SSCP}

Only patients at high risk are required to receive SSCP interventions; however, many patients at lower risk may benefit from certain SSCP interventions, and clinicians should use their judgment to select interventions as indicated. At minimum, patients not on the SSCP must be re-screened at least quarterly at treatment plan review, and any positive screen triggers comprehensive suicide risk assessment and SSCP determination. All patients, regardless of risk status, should be provided with crisis information during intake and at quarterly treatment review, including clinic off-hour/crisis numbers, local crisis support services (e.g., mobile crisis, ED, 911), and the National Suicide Prevention Lifeline (1-80o-LIFELINE).

\section{Training procedures}

Agencies were assigned to one of two levels of implementation support, either Basic (BI) or Enhanced (EI) implementation. In the BI condition, large-group $(\sim 300$ participants) webinars for clinic leadership are held monthly to assist with implementation of AIM-SP interventions, data reporting requirements, and training. In addition, all clinical staff in participating clinics (approx. 3 500) were required to take four hours of online distance-learning training on risk assessment, safety planning, the suicide-safer care pathway, and adaptations for children. EI procedures included all BI activities, but also included selection and utilization of site champions (i.e., clinic supervisors provided with advanced clinical training to serve as on-site resources for staff) and attendance at monthly small-group (approx. 10-15 people) learning collaborative meetings that addressed barriers and facilitators for implementing the ZS model. The additional resources required to implement the EI interventions were supported by the grant.

\section{Evaluation procedures}

During the Preparation phase, all measures and materials were prepared, clinics were enrolled, baseline data were collected, site champions were selected, clinical training of staff was initiated, and leadership and site champions began attending large-group webinars (BI) or small-group learning collaboratives (EI). The study employed an effectiveness-implementation Type 1 design (Curran et al., 2012) and cluster randomization (agencies) with stratification by geographic region and agency size (high vs. low annual patient census) to assign agencies to either BI or EI conditions.

During the Implementation phase, AIM-SP clinical procedures were implemented for all newly-enrolled patients, then extended to all patients at quarterly treatment plan review after six months. Clinic leadership and site champions continued to attend webinars (BI) or learning collaboratives (EI), data reporting began, and quality improvement information and technical support were provided. The data collection protocol tracks individual patient- and aggregate clinic-level data on the receipt of the AIM-SP clinical components as well as proximal outcomes (treatment attendance, emergency care, and hospitalization). Distal outcomes (suicide deaths/attempts) were obtained via statewide mandated reporting of all suicide attempts and deaths to the New York State Integrated Mandated Reporting System (NIMRS; NYS Office of Mental Health, 2016) and NYS Medicaid data. The 12 months after implementation is the Maintenance phase, during which clinics sustain performance without grant-funded technical, clinical, or implementation support, and the Follow-up phase is 12 months after maintenance concludes, used to assemble suicide data and query the National Death Index for deaths occurring outside NYS.

The implementation phase began in October 2017 , so data are not yet available. The primary planned analyses include comparison of the effectiveness of EI and $\mathrm{BI}$ conditions in reducing suicidal behaviors (attempts and deaths), psychiatric hospitalizations, and ED visits. We will also conduct a historical control comparison analysis to compare outcomes within agencies before and after AIM-SP implementation, and a matched-cohort comparison analysis to compare outcomes between agencies who are and are not participating in the project. Further, we will use mixed qualitative-quantitative approaches to compare EI and BI conditions on implementation and sustainability of the ZS model, evaluating agency- and provider-level predisposing, enabling, and reinforcing factors affecting implementation success, as well as rates and quality of ZS components (process/impact evaluation) during implementation, maintenance, and follow-up periods.

\section{Conclusions}

Suicide is an enormous public health concern, and ZS has been promoted as a way to reduce suicides for those receiving services. Our study is the largest implementation and evaluation of the ZS approach in outpatient clinics ever conducted. Results from this study will provide crucial insight regarding how to best adopt and disseminate empirically-supported suicide-safe care, thereby reducing preventable loss of life. 
Acknowledgements:

Research reported in this manuscript was supported by the National Institute of Mental Health of the National Institutes of Health under award number R01MH112139 (PI: Stanley). The content is solely the responsibility of the authors and does not necessarily represent the official views of the National Institutes of Health.

\section{REFERENCES}

The AESCHI Working Group. (2018). Retrieved on March 10, 2018 from: http://www.aeschiconference.unibe.ch/the_aeschi_group.htm

Ahmedani, B. K., Simon, G. E., Stewart, C., Beck, A., Waitzfelder, B. E., Rossom, R., et al. (2014). Health care contacts in the year before suicide death. I Gen Intern Med, 29, 870-877.

American College of Emergency Physicians. (2017). The Uninsured: Access to Medical Care. Accessed on October 1, 2017 from http://newsroom.acep. org/fact_sheets?item $=30032$.

Brown, G. K., Beck, A. T., Steer, R. A., \& Grisham, I. R. (2000). Risk factors for suicide in psychiatric outpatients: a 20-year prospective study. I Consult Clin Psychol, 68, 371.

Brown, G. K., Ten Have, T., Henriques, G. R., Xie, S. X., Hollander, I. E., \& Beck, A. T. (2005). Cognitive therapy for the prevention of suicide attempts: a randomized controlled trial. JAMA, 294, 563-570.

Center for Disease Control and Prevention (CDCP). (2017). 2015, Suicide Injury Deaths and Rates per 100 000. CDCP Web-based Injury Statistics Query and Reporting System (WISQARS). Retrieved on October 1, 2017 from https://www.cdc.gov/injury/wisqars/ fatal.html.

CDCP. (2016). Data and Statistics. Retrieved on February 1, 2016 from http:// wonder.cdc.gov/ cancer.html and http://www.cdc.gov/dhdsp/data_statistics/index.htm.

Centerstone website. (2016). Retrieved on February 1, 2016 from https:// www.centerstone.org/about/zero-suicide.

Curran, G. M., Bauer, M., Mittman, B., Pyne, I. M., \& Stetler, C. (2012). Effectiveness-implementation hybrid designs: combining elements of clinical effectiveness and implementation research to enhance public health impact. Med Care, 50, 217.

Damschroder, L. I., Aron, D. C., Keith, R. E., Kirsh, S. R., Alexander, I. A., \& Lowery, I. C. (2009). Fostering implementation of health services research findings into practice: a consolidated framework for advancing implementation science. Implement Sci, 4, 50.

Fowler, I. C. (2012). Suicide risk assessment in clinical practice: pragmatic guidelines for imperfect assessments. Psychotherapy, 49, 81.

Hampton, T. (2010). Depression care effort brings dramatic drop in large HMO population's suicide rate. IAMA, 303, 1903-1905.

Harkavy-Friedman I.M. (1993). Suicidal behaviors in adult psychiatric outpatients, I: Description and prevalence. Am I Psychiatry, 150, 108-112.

Ilgen, M. A., Conner, K. R., Roeder, K. M., Blow, F. C., Austin, K., \& Valenstein M. (2012). Patterns of treatment utilization before suicide among male veterans with substance use disorders. Am I Public Health, 102(S1), S88-S92.

Isometsa, E. T., Heikkinen, M. E., Marttunen, M. I., \& Henriksson, M. M. (1995). The last appointment before suicide: is suicide intent communicated?. American I Psychiatry, 152, 919-922.

Jobes, D. A., Wong, S. A., Conrad, A. K., Drozd, I. F., \& Neal-Walden, T. (2005). The collaborative assessment and management of suicidality versus treatment as usual: a retrospective study with suicidal outpatients. Suicide Life-Threat Behav, 35, 483-497.

Kessler, R. C., Borges, G., \& Walters, E. E. (1999). Prevalence of and risk factors for lifetime suicide attempts in the National Comorbidity Survey. Arch Gen Psychiatry, 56, 617-626.
Linehan, M. M., Comtois, K. A., Murray, A. M., Brown, M. Z., Gallop, R. J., Heard, H. L., et al. (2006). Two-year randomized controlled trial and follow-up of dialectical behavior therapy vs therapy by experts for suicidal behaviors and borderline personality disorder. Arch Gen Psychiatry, 63, 757-766.

Luoma, I. B., Martin, C. E., \& Pearson, I. L. (2002). Contact with mental health and primary care providers before suicide: A review of the evidence. Am I Psychiatry, 159, 909-916.

Luxton, D. D., Iune, I. D., \& Comtois, K. A. (2013). Can postdischarge follow-up contacts prevent suicide and suicidal behavior? Crisis, 34, 32-41.

Michel, K., \& Gysin-Maillart, A. (2015). ASSIP - Attempted Suicide Short Intervention Program: A Manual for Clinicians. Boston, MA: Hogrefe Publications.

Michel, K., \& Jobes, D. A. (2010). Building a therapeutic alliance with the suicidal patient. Washington, D.C.: American Psychological Association.

Michel, K., Valach, L., \& Gysin-Maillart, A. (2017). A novel therapy for people who attempt suicide and why we need new models of suicide. Concept paper. Int I Environ Res Public Health, 14, 243. doi:10.339o/ijerph14030243.

NYS Office of Mental Health. (2016). New York State Incident Management \& Reporting System (NIMRS). Accessed on February 1, 2016 from https://www. omh.ny.gov/omhweb/ dqm/bqi/nimrs.

NYS Office of Mental Health. (2017). Psychiatric Services and Clinical Knowledge Enhancement System (PSYCKES). Accessed on March 20, 2017 from http://www.omh.ny.gov/omhweb/ psyckes_medicaid.

New York State Office of Suicide Prevention. (2016). NYS-OMH Quality Management Internal Survey. Unpublished data.

Nock, M. K., Borges, G., Bromet, E. I., Alonso, I., Angermeyer, M., Beautrais, A., et al. (2008). Cross-national prevalence and risk factors for suicidal ideation, plans and attempts. Br I Psychiatry, 192, 98-105.

Posner, K., Brown, G. K., Stanley, B., Brent, D. A., Yershova, K. V., Oquendo, M. A., et al. (2011). The Columbia-Suicide Severity Rating Scale: initial validity and internal consistency findings from three multisite studies with adolescents and adults. Am I Psychiatry, 168, 1266-1277.

Pisani, A., Murrie, D. C., \& Silverman, M. M. (2016). Reformulating suicide risk formulation: From prediction to prevention. Acad Psychiatry, 40, 623629.

Stanley, B. (November, 2017). Zero suicide: Implementation and evaluation in outpatient mental health clinics. Paper presented at the International As sociation for Suicide Research/American Foundation for Suicide Prevention (IASR/AFSP) Suicide Research Summit, Las Vegas, Nevada.

Stanley, B., \& Brown, G. K. (2012). Safety planning intervention: a brief intervention to mitigate suicide risk. Cogn Behav Pract, 19, 256-264.

Suicide Prevention Resource Center. (2017). Zero Suicide website. Retrieved October 1, 2017 from http://zerosuicide.sprc.org.

Trivedi, M. H., Morris, D. W., Wisniewski, S. R., Nierenberg, A. A., Gaynes, B. N., Kurian, B. T., et al. (2013). Clinical and sociodemographic characteristics associated with suicidal ideation in depressed outpatients. Can I Psychiatry, $58,113-122$.

U.S. Department of Health and Human Services [U.S. DHHS]. (2011). Healthy People 2020 Initiative - adolescent health. Retrieved on September 19, 2014 from http://www.healthypeople.gov/2020/topicsobjectives2020/overview. aspx?topicid $=2$

U.S. DHHS Office of the Surgeon General and National Action Alliance for Suicide Prevention. (2012). National Strategy for Suicide Prevention. Washington, DC: HHS.

Wenzel, A., Berchick, E. R., Tenhave, T., Halberstadt, S., Brown, G. K., \& Beck, A. T. (2011). Predictors of suicide relative to other deaths in patients with suicide attempts and suicide ideation: a 3o-year prospective study. I Affect Disord, 132, 375-382.

World Health Organization (WHO). (2017). Suicide data. Retrieved on October 1, 2017 from http://www.who.int/mental_health/prevention/suicide/ suicideprevent/en. 


\section{NOTES}

1 The authors recognize that the name of the "Zero Suicide» Initiative is somewhat controversial. The initial intent of the National Action Alliance and Suicide Prevention Resource Center in selecting such a moniker was to inspire hope and optimism, and convey the belief that suicide deaths could be prevented within healthcare systems. This goal is clearly aspirational and limited to the prevention of suicide within healthcare systems only. Some have raised the concern that the name "Zero Suicide» could foster misconceptions amongst the public or policy makers, who may inaccurately perceive that aspirational goal as being readily attainable, and thus set expectations unrealistically high. Others have suggested that the title could convey the perception that all suicide deaths (not just those occurring in healthcare systems) should have been prevented, which could increase guilt and stigma for survivors who have lost loved ones. While these concerns are valid, the "Zero Suicide» Initiative has already been widely disseminated across the United States and internationally (see zerosuicide.org and zerosuicide. sprc.org for more information on the history of ZS). As such, the authors continue to use the ZS name in this manuscript.

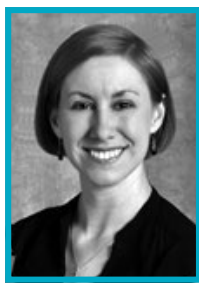

DR. CHRISTA D. LABOULIERE, PH.D. is a clinical psychologist, suicide prevention specialist with the Suicide Prevention - Training, Implementation, and Evaluation (SP-TIE) Program, and Assistant Professor of Clinical Psychology in the Department of Psychiatry, Columbia University.

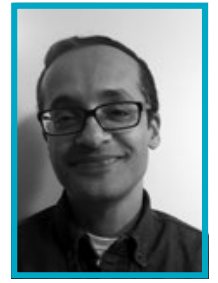

PRABU VASAN, LCSW-R is the project manager for the Suicide Prevention Project, NY Office of Mental Health Bureau for Evidence-Based Services and Implementation Science. He received a Master's in Social Work from Hunter College School of Social Work.



ANNI KRAMER, MSW is an Implementation Director with the NY Office of Mental Health Bureau for Evidence-Based Services and Implementation Science. She received a Master's in Social Work from Columbia University with a concentration in policy.

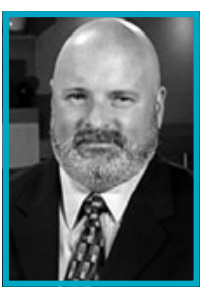

DR. GREGORY BROWN, PH.D. is an internationally-renowned suicide researcher, the Chair of the PhenX Suicide Working Group, and a Research Associate Professor of Clinical Psychology in Psychiatry at the University of Pennsylvania Perelman School of Medicine.



DR. KELLY GREEN, PH.D. is a suicide prevention researcher. Her current research focuses on the development and evaluation of evidence-based practices for suicide prevention, in addition to studying optimal implementation methods to support uptake of these practices in real-world settings.

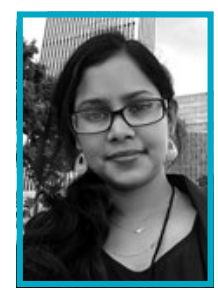

MAHFUZA RAHMAN, M.A. is a data analyst with the NY Office of Mental Health Data Analysis unit of the Bureau for Evidence-Based Services and Implementation Science. She received her Master's in Economics from University at Albany.

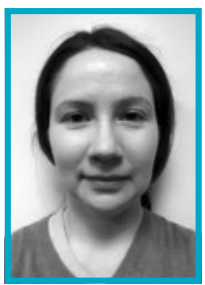

DR. JAMIE KAMMER, PH.D. is a data analyst with the NY Office of Mental Health Data Analysis unit of the Bureau for Evidence-Based Services and Implementation Science. She received her Ph.D. in epidemiology from SUNY Albany School of Public Health.

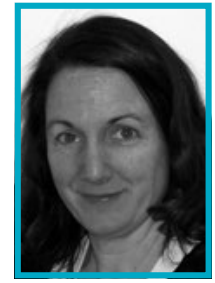

DR. MOLLY FINNERTY, MD is a psychiatrist, Director of the Bureau for Evidence-Based Services and Implementation Science at NYS Office of Mental Health, and a Research Associate Professor in Child and Adolescent Psychiatry, New York University Langone Medical Center.

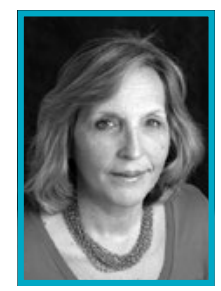

DR. BARBARA STANLEY, PH.D. is an internationally-renowned suicide researcher, the Director of the Suicide Prevention - Training, Implementation, and Evaluation (SP-TIE) Program, and Professor of Medical Psychology (in Psychiatry), Columbia University College of Physicians and Surgeons. Stanley is visiting professor at NSSF. 